\title{
BMJ Open A prospective, observational study investigating the use of carbon monoxide screening to identify maternal smoking in a large university hospital in Ireland
}

\author{
Ciara Marie Edel Reynolds, ${ }^{1,2}$ Brendan Egan, ${ }^{2,3}$ Rachel AK Kennedy, ${ }^{1}$ \\ Eimer G O’Malley, ${ }^{1}$ Sharon R Sheehan, ${ }^{1}$ Michael J Turner ${ }^{1}$
}

To cite: Reynolds CME, Egan B, Kennedy RAK, et al. A prospective, observational study investigating the use of carbon monoxide screening to identify maternal smoking in a large university hospital in Ireland. BMJ Open 2018;0:e022089. doi:10.1136/ bmjopen-2018-022089

- Prepublication history and additional material for this paper are available online. To view these files, please visit the journal online (http://dx.doi. org/10.1136/bmjopen-2018022089).

Received 1 February 2018 Revised 12 June 2018 Accepted 20 June 2018

Check for updates

(C) Author(s) (or their employer(s)) 2018. Re-use permitted under CC BY-NC. No commercial re-use. See rights and permissions. Published by BMJ.

${ }^{1}$ UCD Centre for Human Reproduction, Coombe Women and Infants University Hospital, Dublin, Ireland

${ }^{2}$ UCD School of Public Health, Physiotherapy and Sports Science, University College Dublin, Dublin, Ireland

${ }^{3}$ School of Health and Human Performance, Dublin City University, Dublin, Ireland

Correspondence to

Miss Ciara Marie Edel Reynolds; ciara.reynolds@ucdconnect.ie

\section{ABSTRACT}

Objectives This study evaluated breath carbon monoxide (BCO) testing in identifying maternal smokers as well as the difference between disclosers and nondisclosers of smoking status. We also investigated if other extrinsic factors affected the women's BCO levels in pregnancy.

Design A prospective observational study.

Setting A university obstetric hospital in an urban setting in Ireland.

Participants Women $(n=250)$ and their partners $(n=54)$ were recruited at their first antenatal visit. Women $<18$ years and those who did not understand English were excluded. A booking history, including recording of smoking status, was collected by midwives. Following this, women were recruited and completed a detailed research questionnaire on smoking and extrinsic/environmental BCO sources. A BCO test was performed on both the woman and her partner.

Primary and secondary outcome measures The number of self-reported smokers and those that were positive on the BCO test. The characteristics of women who disclosed and did not disclose smoking status. The effect of extrinsic factors on the BCO test results. Results Based on the receiver-operating characteristic curve, a BCO cut-off point of $\geq 3$ ppm was the optimal level to identify ongoing smoking. At booking history, $15 \%$ of women reported as current smokers. Based on BCO levels $\geq 3 \mathrm{ppm}$ combined with self-reported smoking in the research questionnaire, the rate increased to $25 \%$. Nondisclosers had similar characteristics to non-smokers. No extrinsic factors affected maternal BCO levels.

Conclusions Based on self-report and BCO levels, a quarter of women presenting for antenatal care continued to smoke, but only $60 \%$ reported their smoking to midwives. BCO measurement is an inexpensive, practical method of improving identification of maternal smoking, and it was not effected by extrinsic sources of BCO. Improved identification means more smokers can be supported to stop smoking in early pregnancy potentially improving the short-term and long-term health of both mother and child.

\section{Strengths and limitations of this study}

- Sensitivity and specificity analysis was carried out to identify the optimal cut-off point to determine smoking as there are wide variations and no consensus in the literature, particularly in pregnant populations.

- Our study collected details of daily self-reported exposure to extrinsic sources of $\mathrm{CO}$ and directly measured exposure to passive smoking using breath $\mathrm{CO}$ in a subset of partners.

- Carbon monoxide analysis, although the most practical and feasible screening tool to detect smoking in a large cohort, can only detect exposure from the previous 4 hours.

\section{BACKGROUND}

Maternal smoking is arguably the most important modifiable risk factor for adverse pregnancy outcomes including perinatal death. ${ }^{1}$ Passive smoking is also linked to adverse outcomes, in particular fetal growth restriction. $^{2}{ }^{3}$ Smoking cessation either pre-pregnancy or in the first half of pregnancy can normalise fetal growth. ${ }^{4}$

Although smoking rates in non-pregnant adult women are falling in Ireland, over 1 in 10 women report that they continue to smoke at their first antenatal visit. ${ }^{5}$ Similar rates have been reported in other developed countries. ${ }^{67}$ As many as three quarters of women may not disclose their smoking status when they present to maternity services; however, there are large discrepancies in the literature regarding rates of non-disclosure and none to date have been reported for Ireland. ${ }^{89}$

Non-disclosure of smoking leads to inaccurate smoking prevalence rates and missed opportunities to offer advice and support to quit. ${ }^{10}$ This has led to the use of biochemical markers to identify people who fail to disclose 
their smoking behaviour. ${ }^{11-13}$ The most commonly used biomarkers include serum carboxyhaemoglobin or cotinine, a by-product of nicotine, from urine, saliva or blood samples. ${ }^{14}$ These methods, although valid, reliable and sensitive to cigarette smoke exposure of up to 20 hours, can be invasive, inconvenient and expensive as they require laboratory involvement for analysis. Cotinine samples can cost up to approximately US\$20 a sample, and results can be affected by the use of nicotine replacement therapy. ${ }^{1516}$ Thus, this method may be only feasible in a research setting.

A breath carbon monoxide (BCO) test is a more appropriate alternative biomarker of cigarette exposure for routine screening as it costs as little as US\$1 per sample. ${ }^{15}$ Furthermore, the BCO test is safe, quick, non-invasive and yields immediate results at the point of care ${ }^{17-19}$ A challenge of BCO testing is the half-life of carbon monoxide $(\mathrm{CO})$. $\mathrm{CO}$ exposure in the previous 3 to 5 hours can be detected by a BCO test and it is, therefore, unable to detect active tobacco exposure from the previous day. ${ }^{10}$ Despite this, BCO correlates well with serum and urine cotinine levels and has shown high sensitivity and specificity in distinguishing between smokers and non-smokers. ${ }^{19}$ Thus, BCO is a feasible option to help identify women who do not disclose their smoking in the antenatal outpatients.

Guidelines recommend the screening of $\mathrm{CO}$ at the first antenatal visit, with the National Institute for Health and Care Excellence (NICE) guidelines in the UK recommending that all women with a positive BCO test are referred to an 'opt-out' stop smoking service (SSS). ${ }^{20} 21$ The screening of all pregnant women with a BCO test has two important purposes. First, it can help identify women who continue to smoke in pregnancy and give staff the opportunity to advise and provide support to quit. Second, the BCO test can ensure that the woman and her baby are not inadvertently in contact with the poisonous gas. ${ }^{20}$ To date, no guidelines have been implemented in Ireland and just one out of all 19 units nationally conduct a BCO test in pregnancy. ${ }^{22}$

$\mathrm{CO}$ is a colourless, odourless, tasteless and poisonous gas that is potentially fatal at high levels. Exposure to $\mathrm{CO}$ is particularly dangerous during pregnancy because it replaces the oxygen available to the fetus, restricts growth and development, and increases the risk of fetal death, developmental disorders and chronic cerebral lesions. ${ }^{23} \mathrm{CO}$ is emitted from cigarette smoke, exhaust fumes and from malfunctioning or poorly ventilated fossil-fuelled/wood-fuelled heating and cooking appliances. ${ }^{20}{ }^{23}$ However, there is a dearth of knowledge of the degree to which these extrinsic factors as well as partners' smoking habits can affect routine $\mathrm{CO}$ screening. ${ }^{24} 25$

The purpose of this study was to evaluate the use of BCO screening to detect cigarette smoking in women presenting to an Irish maternity hospital for antenatal care as well as characterise the difference between disclosers and non-disclosers of smoking status. We also investigated if other extrinsic factors affected the women's' BCO levels in pregnancy.

\section{METHODS}

This prospective observational cohort study was conducted between January and September 2017 in a large Irish university maternity hospital responsible for approximately 8500 deliveries per annum.

There were three sources of data used in this study: maternal booking data collected and computerised by midwives and retrieved by the researcher from the electronic medical record system 'K2', a carbon monoxide breath test conducted by the researcher (CR) and a fully supervised paper-based research questionnaire (figure 1). At the first antenatal visit ('booking visit'), the woman's history was computerised by a trained midwife onto K2. Histories were taken in a standardised manner and included questions regarding a number of lifestyle factors such as self-reported smoking prompted by the K2 system (figure 1).

The women's booking history and first antenatal dating scan are held on the same day at approximately 12 weeks' gestation. Thus, on completion of the booking history, and before women presented for their first antenatal scan, women were informed of the study by the researcher (CR) and advised to attend the Research Office after their dating scan should they wish to participate (figure 1).

On attendance at the Research Office, women were screened for eligibility. Women were ineligible if they were under 18 years of age or did not understand English. Eligible women were then formally invited to participate in the study. Women were informed that the BCO test would assess their exposure to $\mathrm{CO}$ sources such as tobacco smoke, exhaust fumes, poor household ventilation and so on. ${ }^{18}$ Written consent was obtained to provide a sample of expired air and to complete an additional research questionnaire. The questionnaire collected further sociodemographic and lifestyle information, that is, education level, potential environmental exposures to carbon monoxide such as passive smoke and a repeated self-reported smoking status (figure 1). Assurance was given that all data were anonymous and would not affect care in the hospital in order to encourage accurate reporting in the research questionnaire. Other known environmental exposures to $\mathrm{CO}$ were collected due to their potentially confounding nature in accurately identifying smokers. ${ }^{18}$

Partners in attendance with the woman at the first visit were also offered participation in the study. The partner was fully informed of the study procedures and written consent was obtained. The partners followed the same study procedures as the pregnant woman. $\mathrm{BCO}$ was performed and the research questionnaire was completed.

BCO levels were performed using the inexpensive, handheld Bedfont piCO+ Smokerlyzer (Bedfont Scientific, Kent, UK). To perform the breath test, women were asked to exhale completely, inhale fully and breath-hold 
At first antenatal visit ('booking') (mean 12 weeks gestation)

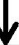

Women book with antenatal midwives who computerise clinical and lifestyle details onto the hospitals electronic medical record system (K2)

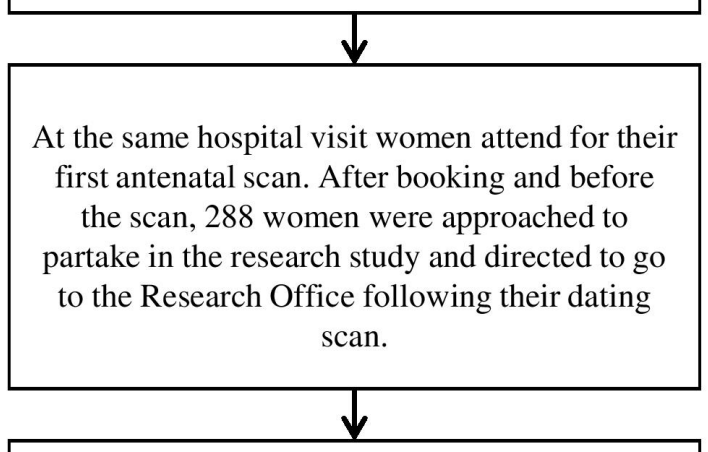

All 288 women attended dating scan
Data collected and computerised by midwives using prompts from the electronic medical record system:

-Height and weight measured, BMI calculated - Characteristic data: age, parity, employment status, nationality, marital status, pregnancy intention, current and previous drug and alcohol use

-Self-reported current smoking status categorised into never smoked, ex- or current smoker

- Number of cigarettes per day categorised into: occasional, 1-5 cigarettes daily, 6-10 cigarettes daily, 11-20 cigarettes daily or $>20$ cigarettes daily
Following the dating scan, 270 women attended the Research Office. Women were informed of the study procedures. Twenty women declined participation due to time constraints. Written consent was obtained from 250 women and further data was then immediately collected by the researcher.
Figure 1. Flow diagram of participant recruitment and data collection.
18 women did not attend Research Office post scan

Data collected by the researcher using a fully supervised paper based questionnaire:

- A carbon monoxide breath (BCO) test was carried out and results recorded in parts per million (ppm) -If accompanied by a partner they were also asked to partake in a BCO test and an identical supervised questionnaire was completed - Characteristic data: years in continuous education, age at completion of full time education - Clinical conditions such as asthma, bronchiectasis, thyrotoxicosis, haemolytic anaemia ${ }^{15}$

-Self-reported current smoking status categorised into: never smoked, ex- or current smoker

-Number of cigarettes per day in the absolute value and categorised into: occasional, 1-5 cigarettes daily, 6-10 cigarettes daily, 11-20 cigarettes daily or $>20$ cigarettes daily

- Time since last cigarette in minutes

-If multiparous, smoking behaviour in the previous pregnancy

-Passive smoking data: exposed to passive smoke daily and if so, how long per day exposed to passive cigarette smoker (recorded in minutes)

-Other known sources of CO: Daily use of motor vehicle, lives near a main road, lives in a built-up urban area, uses fossil fuel in the home daily, in frequent chimney clean, infrequent boiler service. ${ }^{18}$

Figure 1 Flow diagram of the studies' data collection and recruitment processes. BMI, Body Mass Index. 
for 15 seconds. At the end of the breath hold, the women were asked to exhale slowly and fully into the Smokerlyzer device. Safety protocols were put in place to minimise the risk of missing potential cases of $\mathrm{CO}$ poisoning. ${ }^{20}$ The Smokerlyzer measures BCO levels in parts per million (ppm). Breath holding allows the $\mathrm{CO}$ in the blood to form equilibrium with the $\mathrm{CO}$ in the alveolar air. This technique is responsible for the high level of correlation between breath $\mathrm{CO}$ levels and $\mathrm{COHb}$ concentration. $^{26}$

We calculated that recruitment of 233 women allowed for detection of a 10\% rate of non-disclosure (power $99 \%$, significance $5 \%$ ). Due to large variations in the cut-off criteria used previously to distinguish between smokers and non-smokers, a receiver-operating characteristic (ROC) plot was undertaken. ${ }^{13} 14252728$ The ROC assessed the accuracy of the BCO test in predicting smoking and the BCO level (ppm) with the highest combined sensitivity and specificity value was used as the cut-off. Women who had a CO level greater than the cut-off point but reported as a non-smoker were categorised as non-disclosers.

All results were analysed by the SPSS statistical package V.24. Descriptive statistics were used to describe the characteristics of the study cohort. Normality of data was assessed using visual inspection of histograms, the data skewness and kurtosis and the Kolmogorov-Smirnov test. Continuous data were reported as means and SD if normally distributed and median and IQRs if data were non-normally distributed. Categorical data were reported as proportions. Chi-squared, analysis of variance (ANOVA) and Mann Whitney U were used to assess differences between groups in terms of proportions, means and medians respectively. Associations between CO levels and other variables were carried out using Spearman's correlations. Missing data are presented in the footnotes of tables.

\section{Patient and public involvement}

Previous research has shown that just one out of the 19 maternity units in Ireland conduct the recommended CO screening to identify maternal smokers. ${ }^{22}$ Furthermore, there is a dearth of information on the disclosure rate of maternal smoking in an Irish population. This was the stimulus for our research question.

The patients were not directly involved in the study design, however, the study questionnaire was piloted on ten patients who provided feedback on the questions included. Patients were also not involved in the recruitment process, however, the Hospital Research Ethics Committee includes members of the public involved in reviewing the methods, patient information leaflets, questionnaires and consent form.

The results of our study were not disseminated to the study population. Results will be presented locally to educate staff on our findings with the aim of implementing BCO screening to identify maternal smokers in the hospital.
RESULTS

The ROC results showed that BCO levels measured in parts per million (ppm) were predictors of maternal cigarette smoking (area under the curve $=0.93, \mathrm{p}<0.001$ ) (online supplementary figure 1). The sensitivity and specificity curves crossed at a cut-off point of $3 \mathrm{ppm}$ (online supplementary figure 2). The highest combined sensitivity and specificity of maternal smoking was also at the CO level 3ppm (online supplementary table 1).

Two hundred and eighty-eight women were offered participation in the study of which 250 were recruited. Of the 38 women who did not take part, 20 declined due to time constraints and 18 left immediately after their scan without reason for non-participation. Verified smoking was defined as having a CO level $\geq 3 \mathrm{ppm}$ and/or self-reported smoking either at the first antenatal visit or on the research questionnaire.

Table 1 shows the characteristics of the study group analysed by verified smoking status. Verified maternal smokers $(n=63)$ were more likely to be younger (mean difference 3.4 years, $95 \%$ CI 1.9 to 4.9 , p<0.001), unemployed $(43 \%$ vs $22 \%, \mathrm{p}<0.001)$ and single $(77 \%$ vs $39 \%$, $\mathrm{p}<0.001)$ compared with non-smokers $(\mathrm{n}=187)$. They also spent fewer years in continuous full-time education (mean difference 1.9 years, 95\% CI 0.6 to $3.1, \mathrm{p}<0.01$ ) and finished full-time education at a younger age (mean difference 2.8 years, $95 \%$ CI 1.2 to $4.2, \mathrm{p}<0.001$ ) than non-smokers.

Median BCO levels and rates of $\mathrm{BCO}<3$ and $\geq 3$ ppm by maternal characteristics and $\mathrm{CO}$ sources are shown in tables 2 and 3. Of all known CO sources that were examined, self-reported maternal smoking in the current and previous pregnancy and cigarette quantity were the only factors that were associated with an increased median BCO level above 3 ppm.

Online supplementary table 2 shows that on further examination, using correlation analysis, the number of self-reported cigarettes per day had the strongest association with BCO test levels $(\mathrm{r}=0.61, \mathrm{p}<0.001)$ followed by time since last cigarette $(\mathrm{r}=-0.51, \mathrm{p}<0.01)$. Hours exposed to passive smoking was also associated with BCO levels $(\mathrm{r}=0.31, \mathrm{p}<0.01)$. However, when self-reported active smokers were removed from this analysis, this association did not persist $(r=-0.06, \mathrm{NS})$.

BCO tests were performed on 54 partners of the pregnant women $(22 \%)$. The mean age of the partners was 33.1 years (6.5 years), $98.1 \%$ were men, $83.3 \%$ lived with their pregnant partner and the median BCO level of the partners was $2.0 \mathrm{ppm}$ (IQR $4.5 \mathrm{ppm}$ ). Twenty-eight per cent $(n=15)$ of partners reported current smoking and five of these had a pregnant partner who also smoked. Of the 26 partners with positive BCO tests, their median levels were 6.0 (IQR 8.0), similar to the median BCO of women with positive tests 7.0 (IQR 8.0). On examination of BCO levels, $48 \%(n=26)$ had a $\mathrm{CO} \geq 3 \mathrm{ppm}$. The BCO levels of partners were weakly associated with the BCO levels of the pregnant women $(r=0.34, p<0.05)$, but when active maternal smokers were removed from analysis, the 
Table 1 Characteristics of the study cohort based on self-reported and breath carbon monoxide confirmed smoking status at the first antenatal visit

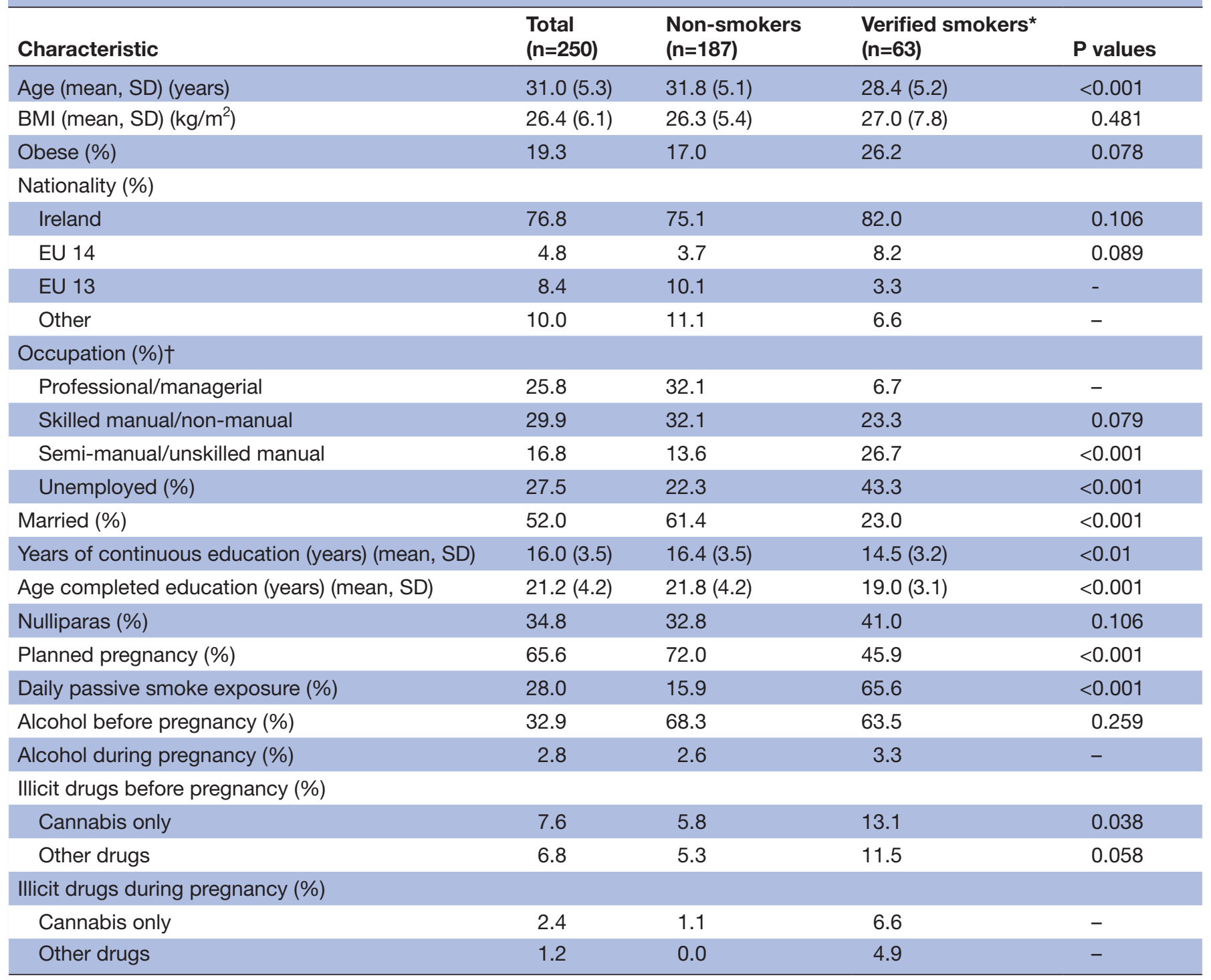

$P$ values indicate significance between non-smokers and verified smokers.

*Women who self-report they are currently smoking and women who had a carbon monoxide level of $\geq 3 \mathrm{ppm}$.

†Missing data $\mathrm{n}=6$.

BMI, Body Mass Index.

- The number of values for this variable was too small to statistically analyse

relationship disappeared. Median BCO levels in pregnant women were the same regardless of their partners $\mathrm{CO}$ levels being $<3$ or $\geq 3$ ppm.

Maternal characteristics of the disclosers and non-disclosers of smoking status were compared (table 4). Non-disclosers were classified as women who did not report smoking at their first antenatal visit but had a CO level $\geq 3 \mathrm{ppm}$ and/or self-reported smoking in the research questionnaire. Non-disclosers had a lower median BCO level than disclosers (10.0 ppm (IQR 8.0) vs $4.0 \mathrm{ppm}$ (IQR 3.0), $\mathrm{p}<0.01$ ). Non-disclosers were older than disclosers when they finished full-time education (20.9 years (IQR 3.9) vs 17.9 years (IQR 2.1), $\mathrm{p}<0.05$ ) and spent more years in continuous full-time education (16.5 years (IQR 3.6) vs 13.4 years (IQR 2.4), $\mathrm{p}<0.01$ ).
They were also more likely to have planned their pregnancy $(60 \%$ vs $37 \%, \mathrm{p}<0.05)$, less likely to have smoked in a previous pregnancy ( $20 \%$ vs $55 \%, \mathrm{p}<0.01)$ and spend less time around passive smoking daily (1.5 hours (IQR 1.6) vs 3.9 hours (IQR 3.5), $\mathrm{p}<0.05$ ).

Changes in self-reported smoking status from the first antenatal visit to self-reported smoking status collected in the research questionnaire are shown in online supplementary table 3 . The largest difference was seen in women who reported 'never smoking' at the first antenatal visit to midwives with $16 \%$ changing their status to 'ex-smoker' on the research questionnaire. Six other women who reported they were never smokers to midwives at the first antenatal visit had a $\mathrm{CO}$ reading $\geq 3 \mathrm{ppm}$. Of these, one woman changed her self-reporting on the research 
Table 2 Median carbon monoxide levels and rates of breath carbon monoxide below and above cut-off by maternal characteristic

\begin{tabular}{|c|c|c|c|c|c|}
\hline Factor & $\mathbf{n}$ & $\begin{array}{l}\text { CO ppm } \\
\text { (median, IQR) }\end{array}$ & CO <3 ppm (\%) & $\mathrm{CO} \geq 3 \mathrm{ppm}(\%)$ & $P$ values \\
\hline \multicolumn{6}{|l|}{ Occupation } \\
\hline $\begin{array}{l}\text { Skilled manual/non- } \\
\text { manual }\end{array}$ & 73 & $1.0(1.0)$ & 80.8 & 19.2 & $<0.001$ \\
\hline $\begin{array}{l}\text { Semi-manual/unskilled } \\
\text { manual }\end{array}$ & 41 & $2.0(3.5)^{\star \star}$ & 65.9 & 34.1 & $<0.01$ \\
\hline Unemployed & 67 & $2.0(5.0)^{\star}$ & 64.2 & 35.8 & $<0.001$ \\
\hline \multicolumn{6}{|l|}{ Marital status } \\
\hline Married/civil partnership $†$ & 130 & $1.5(1.0)$ & 90.0 & 10.0 & $<0.001$ \\
\hline Single & 120 & $2.0(4.0)^{\star \star \star}$ & 63.3 & 36.7 & $<0.001$ \\
\hline \multicolumn{6}{|l|}{ Pregnancy Intention } \\
\hline Planned $†$ & 164 & $1.0(1.0)$ & 84.8 & 15.2 & $<0.001$ \\
\hline Unplanned & 86 & $2.0(4.0)^{\star \star}$ & 62.8 & 37.2 & $<0.001$ \\
\hline \multicolumn{6}{|l|}{ Age completed education } \\
\hline$<18$ years & 35 & $2.0(6.0)$ & 60.0 & 40.0 & $<0.05$ \\
\hline$\geq 18$ years $\dagger$ & 146 & $1.0(1.0)$ & 85.6 & 14.4 & $<0.001$ \\
\hline \multicolumn{6}{|l|}{ Years of continuous education } \\
\hline$<14$ years & 68 & $1.0(1.0)$ & 67.6 & 32.4 & $<0.001$ \\
\hline >14 years $\uparrow$ & 114 & $1.0(3.0)$ & 88.6 & 11.4 & $<0.001$ \\
\hline
\end{tabular}

$P$ values in final column indicate differences between $\mathrm{CO} \leq 3 \mathrm{ppm}$ and $\mathrm{CO} \geq 3 \mathrm{ppm}$.

${ }^{\star} 0.05,{ }^{\star *} 0.01,{ }^{* \star *} 0.001$; $†$, Reference group.

- The number of values for this variable was too small to statistically analyse

questionnaire to ex-smoker and reported quitting 2 months previous. Two other women reported smoking cannabis, which could be the reason for the $\mathrm{CO} \geq 3 \mathrm{ppm}$. At first visit, 17 potential non-disclosers reported they were ex-smokers. Of these, six disclosed smoking on the research questionnaire. Another five women reported they had only quit since the beginning of pregnancy and one was continuing to smoke cannabis.

Based on self-reported smoking status at the first antenatal visit, $15 \%(38 / 250)$ of women were maternal smokers. Based on self-reported smoking in the research questionnaire, the rate rose to $17 \%(42 / 250)$. When results from the $\mathrm{BCO}$ test levels $\geq 3 \mathrm{ppm}$ were used, the rate increased to $23 \%(57 / 250)$. However, when $\mathrm{BCO}$ levels $\geq 3$ ppm were combined with self-reporting, the rate of maternal smoking was $25 \%(63 / 250)$. Based on self-reported non-smoking, our study had a rate of non-disclosure of $12 \%$ (25/212). Overall, 39.6\% (25/63) of all maternal smokers did not report as smokers to midwives when booking at their first antenatal visit.

Six women who reported smoking were not detected on $\mathrm{CO}$ screening. All six reported not having a cigarette in the previous 4 hours and five of the six women smoked $\leq 2$ cigarettes daily.

\section{DISCUSSION}

We found that BCO testing in combination with self-reporting of smoking status in a research setting identified $10 \%$ more maternal smokers than self-reporting using routine practice at the first antenatal visit. Two out of five women who continued to smoke in pregnancy were not identified; thus, maternity services were missing the opportunity to provide smoking cessation advice and support.

There is no consensus as to what constitutes the best cut-off point for determining smoking status. Some suggest a CO level as low as 2 ppm and others as high as 10 ppm. ${ }^{1428-32}$ Due to the conflicting appropriate cut-off points in the literature, we undertook a sensitivity and specificity analysis. ${ }^{30}$ Similar to a large American longitudinal study, we identified a cut-off point of $3 \mathrm{ppm}$ as the optimal to distinguish smokers from non-smokers in terms of limiting both false-positive and false-negative 
Table 3 Median maternal carbon monoxide levels and rates of breath carbon monoxide below and above cut-off by carbon monoxide sources

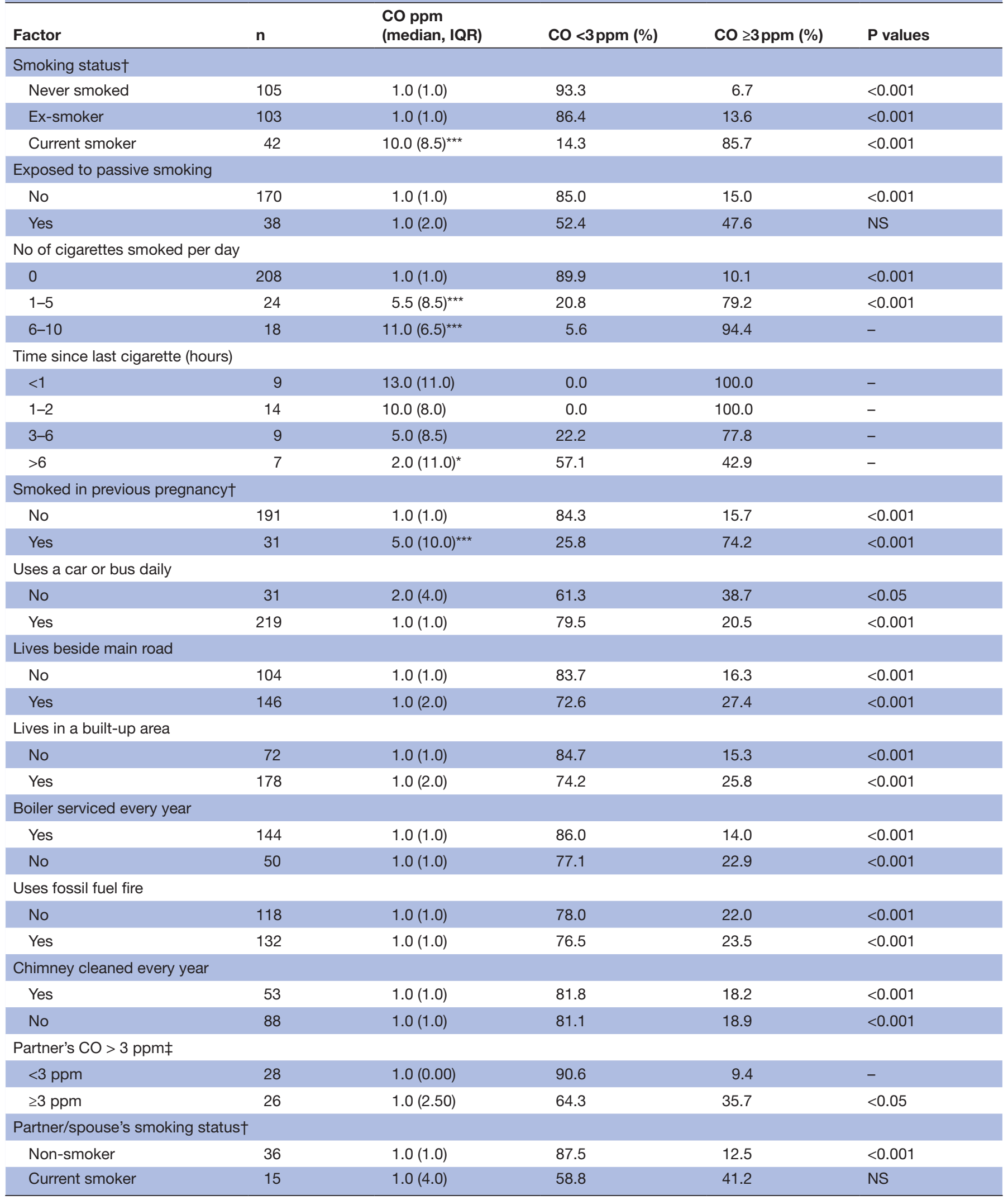


Table 3 Continued

\begin{tabular}{llllll}
\hline Factor & $\mathrm{n}$ & $\begin{array}{l}\text { CO ppm } \\
\text { (median, IQR) }\end{array}$ & CO $<3$ ppm (\%) & CO $\geq 3$ ppm (\%) & P values \\
\hline
\end{tabular}

$P$ values in final column indicate differences between $\mathrm{CO} \leq 3 \mathrm{ppm}$ and $\mathrm{CO} \geq 3 \mathrm{ppm}$.

${ }^{*} 0.05,{ }^{* *} 0.01,{ }^{* * *} 0.001$.

†Based on self-reported smoking status.

- The number of values for this variable was too small to statistically analyse $\ddagger$ Missing data $n=90$.

NS, not significant.

results and maximising identification of smokers with a high degree of certainty. ${ }^{30}$ Few studies have previously undertaken their own ROC, making it difficult to interpret the sensitivity and specificity of results.

There is a dearth of knowledge on what factors other than active smoking can effect BCO levels and SSS staff often find it difficult to explain high results in non-smokers. ${ }^{25}$ Our study collected data on other potential extrinsic sources of CO that may have contaminated results. Other studies do not take into account daily passive smoke exposure, partners BCO levels or sources such as motor vehicle use, fossil fuel exposure, gas/oil boiler servicing practices, ventilation and so on. These factors did not affect median BCO levels in women in the present study and did not increase rates of BCO levels $\geq 3$ ppm. Fifty-four partners took part in this study. We found a weak positive relationship between partner BCO levels and maternal BCO; however, when active smokers were excluded, no relationship existed. One other study, in non-pregnant adults, examined the effect of other sources of CO on BCO test levels and found that gender and motor vehicle use were associated with higher CO levels. However, the differences were minimal $(<1$ ppm $) .^{18}$

A limitation of our study is that we did not collect cotinine samples for verification of smoking status; however, our aim was not to compare screening methods but to report the levels of non-disclosures in Ireland using current guidelines. ${ }^{21}$ Furthermore, our lower cut-off point provided high sensitivity values and has been supported by previous research that also identified this value as optimal when identification of smoking abstinence with a high degree of certainty is of high importance. ${ }^{30}$

Our study found a self-reported smoking rate of $15 \%$, $4 \%$ higher than the rate reported in our previous study that analysed all deliveries in our hospital in $2015 .^{5}$ It is unlikely that the rate has risen, and this higher rate may be due to the convenience sampling employed.

\begin{tabular}{|c|c|c|c|}
\hline & $\begin{array}{l}\text { Disclosers } \\
(n=38)\end{array}$ & $\begin{array}{l}\text { Non-disclosers } \\
(n=25)\end{array}$ & $P$ values \\
\hline BCO level (ppm) (median, IQR) & $10.0(8.0)$ & $4.0(3.0)$ & $<0.01$ \\
\hline Age (years) (mean, SD) & $27.3(5.0)$ & $29.7(5.2)$ & NS \\
\hline BMI $\left(\mathrm{kg} / \mathrm{m}^{2}\right)$ (mean, SD) & $26.5(8.4)$ & $27.7(7.1)$ & NS \\
\hline Married (\%) & 15.8 & 32.0 & NS \\
\hline Nulliparas (\%) & 34.2 & 52.0 & NS \\
\hline Planned pregnancy (\%) & 36.8 & 60.0 & $<0.05$ \\
\hline Age completed education (years) (mean, SD) & $17.9(2.1)$ & $20.9(3.9)$ & $<0.05$ \\
\hline Continuous years of education (mean, SD) $)^{*}$ & $13.4(2.4)$ & $16.5(3.6)$ & $<0.01$ \\
\hline Weekly alcohol before pregnancy (\%) & 57.9 & 72.0 & NS \\
\hline Alcohol binge before pregnancy (\%) & 23.7 & 52.0 & $<0.01$ \\
\hline Drug use before pregnancy (\%) & 26.3 & 20.0 & NS \\
\hline Weekly alcohol in pregnancy (\%) & 2.6 & 4.0 & - \\
\hline Alcohol binge in pregnancy (\%) & 2.6 & 0.0 & - \\
\hline Drug use in pregnancy (\%) & 10.5 & 12.0 & - \\
\hline Smoked in previous pregnancy (\%) & 55.3 & 20.0 & $<0.01$ \\
\hline Exposed to passive smoked daily (\%) & 73.7 & 56.0 & NS \\
\hline Exposure to passive smoke (hours) (mean, SD) & $3.9(3.5)$ & $1.5(1.6)$ & $<0.05$ \\
\hline
\end{tabular}

$P$ values in final column indicate differences between disclosures and non-disclosures.

*Missing data $\mathrm{n}=67$.

- The number of values for this variable was too small to statistically analyse

$\mathrm{BCO}$, breath carbon monoxide; BMI, Body Mass Index; NS, not significant. 
Our study distinguishes characteristics between smokers and non-disclosers unlike previous studies that compared verified smokers with non-smokers. ${ }^{13}$ We found non-disclosers had more similar characteristics to non-smokers than smokers. This could be due to a number of reasons. First, we used a lower cut-off point compared with other studies in pregnant populations. ${ }^{25} 2832$ Another study that carried out an ROC curve found its highest specificity and sensitivity at the cut-off point $>4 \mathrm{ppm}$; however, this cut-off had a lower sensitivity value (0.79) than our study $(0.86) .{ }^{28}$ Our studies' lower cut-off point may therefore be too sensitive and include non-smoking women in the non-disclosure group (false positives). If our cut-off was raised to that of other studies, however, our sensitivity would be reduced and fewer smokers would be identified correctly.

Prior to implementation of the NICE guideline in the UK, healthcare staff were worried that that BCO testing would unjustly accuse women who do not smoke of doing so and that it would affect their relationships with the women.${ }^{25}$ However, following implementation, they found it had little effect on their relationships with women and the SSS staff found that it provided them with a unique opportunity to address second-hand smoke, smoke-free homes and the effects of smoking around children with non-smokers who may be regularly exposed to passive smoke. $^{25}$

For healthcare professionals who continue to have concerns over false positives being wrongly accused of smoking and referred to SSS, an alternative pathway could be implemented whereby cotinine is sampled and tested only in self-reported non-smokers who have a high BCO level in order to keep the expense on maternity services as low as possible.

A further concern is that women who may smoke but did not report doing so at their first appointment may not wish to receive cessation advice. However, guidelines recommend an opt-out referral system where women who are identified as smokers in early pregnancy and those who do not specifically object are referred to smoking cessation services. ${ }^{21}$ Thus, this non-mandatory referral system is centred on the patient's best interests and it does not overrule personal choice.

A number of different rates of non-disclosure have been reported in the literature, from as low as $5 \%$ to as high as $73 \%$, but it is difficult to compare these results with our study. ${ }^{8}$ First, the definition of 'non-disclosure' or 'mis-categorisation' is not standardised across studies. Different denominators are used. Some studies use the number of positive tests whereas others use total population, total self-reported non-smokers or self-reported quitters. ${ }^{12} 133334$ Second, studies to date have used conflicting cut-off points to verify smoking, for example, some use standard cut-off points, some use ROCs to find the optimal for their population and others use both, which demonstrate disparity in results. ${ }^{12} 3335$

Additionally, the samples in previous studies were taken at different time points in pregnancy. Our study took
BCO samples at the beginning of pregnancy. However, previous research found that non-disclosure rates are increased from the beginning to later in pregnancy. ${ }^{13} 35$ Sampling at the first visit is preferable because early identification and successful intervention in the first half of pregnancy has the potential to normalise fetal growth. ${ }^{4}$

A UK study with similar recruitment methods but a higher BCO cut-off point of $>4$ ppm reported that $22.9 \%$ of all smokers did not disclose smoking at booking, much lower than our $39.6 \% .^{32}$ However, this higher cut-off point was previously criticised for missing both self-reported smokers and smokers verified by cotinine. ${ }^{28} 36$

In conclusion, self-reporting of maternal smoking leads to missed opportunities to provide smoking cessation advice and support from the beginning of pregnancy. BCO screening can improve identification of smokers at the first antenatal visit. This screening complements routine history taking but should not replace it as this test may produce a false negative in smokers who have not had a cigarette in the previous 4 hours. Screening in early pregnancy should use a low cut-off value because a once-off test resulting in a false-positive result, in this case, is preferable to a false-negative result. BCO levels correlate with self-reported quantity of cigarettes per day and also with timing of smoking and do not appear to be affected by extrinsic carbon monoxide sources. Finally, cotinine may need to be used as an adjunct to CO screening in women with high CO levels who report that they are non-smokers to rule out a false-positive test.

Acknowledgements We acknowledge with gratitude the Hospital's fundraising arm Friends of the Coombe for supporting this research.

Contributors CMER contributed to the conception and design of the study, performed the analysis of the data, interpreted data and wrote and edited this original article. RAKK, EGOM and SRS contributed to the writing and editing of this article. MJT and BE contributed to the conception of the study, interpretation of data as well as contributing to the writing and editing of this article.

Funding This research received no specific grant from any funding agency in the public, commercial or not-for-profit sectors.

Competing interests None declared.

Patient consent Obtained.

Ethics approval The study was approved by the Research Ethics Committee of Coombe Women and Infants University Hospital (17-2015).

Provenance and peer review Not commissioned; externally peer reviewed.

Data sharing statement Additional unpublished data are available. For further details, contact CMER (ciara.reynolds@ucdconnect.ie).

Open access This is an open access article distributed in accordance with the Creative Commons Attribution Non Commercial (CC BY-NC 4.0) license, which permits others to distribute, remix, adapt, build upon this work non-commercially, and license their derivative works on different terms, provided the original work is properly cited, appropriate credit is given, any changes made indicated, and the use is non-commercial. See: http://creativecommons.org/licenses/by-nc/4.0/.

\section{REFERENCES}

1. Cnattingius $S$. The epidemiology of smoking during pregnancy: smoking prevalence, maternal characteristics, and pregnancy outcomes. Nicotine Tob Res 2004;6Suppl2:S125-40.

2. Rubin DH, Krasilnikoff PA, Leventhal JM, et al. Effect of passive smoking on birth-weight. Lancet 1986;2:415-7. 
3. Martinez FD, Wright AL, Taussig LM. The effect of paternal smoking on the birthweight of newborns whose mothers did not smoke. Group Health Medical Associates. Am J Public Health 1994:84:1489-91.

4. Lieberman E, Gremy I, Lang JM, et al. Low birthweight at term and the timing of fetal exposure to maternal smoking. Am J Public Health 1994;84:1127-31.

5. Reynolds CME, Egan B, McKeating A, et al. Five year trends in maternal smoking behaviour reported at the first prenatal appointment. Ir J Med Sci 2017;186:971-9.

6. European Perinatal Health Report (2010) The health of pregnant women and babies in Europe. 2010 http://www.europeristat.com/ images/European\%20Perinatal\%20Health\%20Report_2010.pdf (accessed 2 Feb 2016).

7. Reitan T, Callinan S. Changes in smoking rates among pregnant women and the general female population in Australia, Finland, Norway, and Sweden. Nicotine Tob Res 2017;19:282-9.

8. Webb DA, Boyd NR, Messina D, et al. The discrepancy between selfreported smoking status and urine continine levels among women enrolled in prenatal care at four publicly funded clinical sites. $J$ Public Health Manag Pract 2003;9:322-5.

9. Pickett KE, Rathouz PJ, Kasza K, et al. Self-reported smoking, cotinine levels, and patterns of smoking in pregnancy. Paediatr Perinat Epidemiol 2005;19:368-76.

10. Russell T, Crawford M, Woodby L. Measurements for active cigarette smoke exposure in prevalence and cessation studies: why simply asking pregnant women isn't enough. Nicotine Tob Res 2004;6Suppl2:S141-51.

11. Shipton D, Tappin DM, Vadiveloo T, et al. Reliability of self reported smoking status by pregnant women for estimating smoking prevalence: a retrospective, cross sectional study. BMJ 2009;339:b4347.

12. Dietz PM, Homa D, England LJ, et al. Estimates of nondisclosure of cigarette smoking among pregnant and nonpregnant women of reproductive age in the United States. Am J Epidemiol 2011:173:355-9.

13. Tong VT, Althabe F, Alemán A, et al. Accuracy of self-reported smoking cessation during pregnancy. Acta Obstet Gynecol Scand 2015;94:106-11.

14. Campbell E, Sanson-Fisher R, Walsh R. Smoking status in pregnant women assessment of self-report against carbon monoxide (CO). Addict Behav 2001;26:1-9.

15. Patrick DL, Cheadle A, Thompson DC, et al. The validity of selfreported smoking: a review and meta-analysis. Am J Public Health 1994;84:1086-93.

16. Benowitz NL, Hukkanen J, Jacob P. Nicotine chemistry, metabolism, kinetics and biomarkers. Handb Exp Pharmacol 2009;192:29-60.

17. Vogt TM, Selvin S, Widdowson G, et al. Expired air carbon monoxide and serum thiocyanate as objective measures of cigarette exposure. Am J Public Health 1977;67:545-9.

18. Cunnington AJ, Hormbrey P. Breath analysis to detect recent exposure to carbon monoxide. Postgrad Med J 2002;78:233-7.
19. Erb P, Raiff BR, Meredith SE, et al. The accuracy of a lower-cost breath carbon monoxide meter in distinguishing smokers from nonsmokers. J Smok Cessat 2015;10:59-64.

20. HSC Public Health Agency. Carbon monoxide screening. Advice for health professionals. http://www.publichealth.hscni.net/publications/ carbon-monoxide-screening-advice-health-professionals.

21. The National Institute for Health and Care Excellence (NICE) Smoking: stopping in pregnancy and after childbirth. Public health guideline.. https://www.nice.org.uk/guidance/ph26.

22. Reynolds CME, Egan B, Cawley S, et al. A national audit of smoking cessation services in Irish maternity units. Ir Med J 2017;110:580.

23. Raub JA, Mathieu-Nolf M, Hampson NB, et al. Carbon monoxide poisoning - a public health perspective. Toxicology 2000;145:1-14.

24. Friedman P, Guo XM, Stiller RJ, et al. Carbon monoxide exposure during pregnancy. Obstet Gynecol Surv 2015;70:705-12.

25. Campbell KA, Bowker KA, Naughton F, et al. Antenatal clinic and stop smoking services staff views on "opt-out" referrals for smoking cessation in pregnancy: a framework analysis. Int J Environ Res Public Health 2016;13:1004.

26. Middleton ET, Morice AH. Breath carbon monoxide as an indication of smoking habit. Chest 2000;117:758-63.

27. West R, Hajek P, Stead L, et al. Outcome criteria in smoking cessation trials: proposal for a common standard. Addiction 2005;100:299-303.

28. Bauld L, Hackshaw L, Ferguson J, et al. Implementation of routine biochemical validation and an 'opt out' referral pathway for smoking cessation in pregnancy. Addiction 2012;107 Suppl 2:53-60.

29. Deveci SE, Deveci F, Açik Y, et al. The measurement of exhaled carbon monoxide in healthy smokers and non-smokers. Respir Med 2004;98:551-6.

30. Javors MA, Hatch JP, Lamb RJ. Cut-off levels for breath carbon monoxide as a marker for cigarette smoking. Addiction 2005;100:159-67.

31. Higgins ST, Heil SH, Badger GJ, et al. Biochemical verification of smoking status in pregnant and recently postpartum women. Exp Clin Psychopharmacol 2007;15:58-66.

32. Campbell KA, Cooper S, Fahy SJ, et al. 'Opt-out' referrals after identifying pregnant smokers using exhaled air carbon monoxide: impact on engagement with smoking cessation support. Tob Control 2017;26:300-6.

33. Boyd NR, Windsor RA, Perkins LL, et al. Quality of measurement of smoking status by self-report and saliva cotinine among pregnant women. Matern Child Health J 1998;2:77-83.

34. Lindqvist $\mathrm{R}$, Lendahls $\mathrm{L}$, Tollbom $\mathrm{O}$, et al. Smoking during pregnancy: comparison of self-reports and cotinine levels in 496 women. Acta Obstet Gynecol Scand 2002;81:240-4.

35. Ford RP, Tappin DM, Schluter PJ, et al. Smoking during pregnancy: how reliable are maternal self reports in New Zealand? J Epidemio Community Health 1997;51:246-51.

36. Jatlow P, Toll BA, Leary V, et al. Comparison of expired carbon monoxide and plasma cotinine as markers of cigarette abstinence. Drug Alcohol Depend 2008;98:203-9. 